\title{
Counting the costs of US research
}

President Carter's science adviser, Dr Frank Press, has intervened in a heated dispute between universities and the administration over how much universities should be reimbursed for carrying out federallysponsored research.

Several years of frequently acrimonious debate, in particular over the allocation of 'indirect' costs such as libraries, utilities and administration, have been brought to a head by last month's publication by the Otfice of Management and Budget (OMB) of proposed changes in 'cost principles'. These are the rules by which the administration lays down what a university can and cannot charge to a federal agency for carrying out sponsored research projects.

According to $\mathrm{OMB}$, the purpose of the proposed changes is primarily to simplify accounting procedures by providing a common framework for estimating allowable costs that can bc applied by all federal agencies who sponsor such research. At present each agency has slightly different rules, making it difficult to prepare an overall picture for public scrutiny.

Furthermore it is claimed that the proposed changes could result in universities having to find up to $\$ 200$ million from other sources to sustain research efforts at the current level, a move whose net result might include a reduction in the amount of research carried out

Recent years have seen a dramatic growth in indirect costs both in real terms and as a proportion of direct costs. Many large institutions now adding 60 to $70 \%$ on top of a scientist's grant application. And this has led to criticism from Congress (and frequently from scientists as well) that such costs are not always justifiable.

The changes proposed by OMB are the result of a process begun two years ago when the department of Health, Education and Welfare (HEW), the agency responsible for over half of the $\$ 3.3$ billion of federal research and development carricd out by US universities, was directed to develop a system for sharing costs fairly and equitably' between the two parties.

The response of many universities to OMB's resultant proposals is that. as they now stand, they are neither fair nor equitable, but would impose a greater financial burden than is borne by private corporations of other nonprofit institutions, and will, in the words of the dean of research at Stanford University, "further discourage the development of promising young researchers".
Two proposals in particular have been attacked for their inancial implications: the first limiting the recovery of library costs to those incurred only by fuull-time research workers and the second disallowing the costs of providing services for graduate students.

OMB officials say that the new proposals have not been prepared with any conscious intention of placing additional financial burdens on the universities, although admitting that some may suffer by having to adopt less-favourable accounting procedures.

However the debate is not merely financial, but reflects deeper concerns about the politics of basic science. And OMB faces a practical dilemma in its attempts to develop an accounting system that meets both Congress's demands for public accountability and university scientists' claims for flexi-

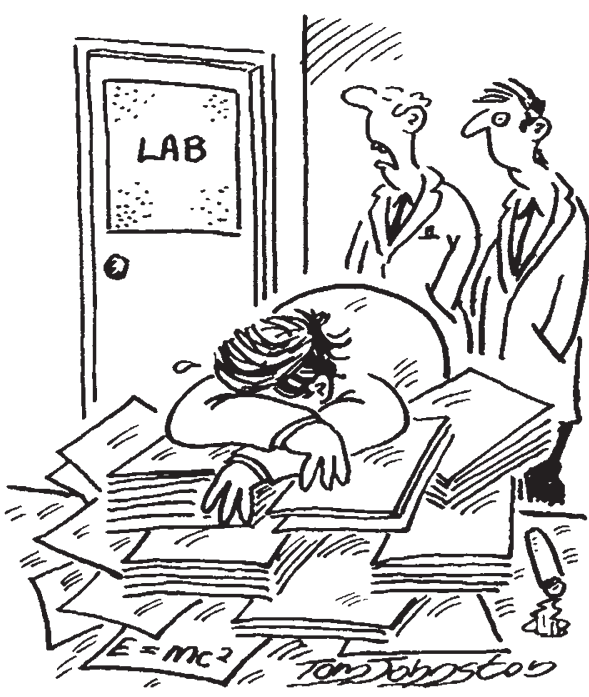

'Poor Chuck, lost his discovery among the grant application forms!'

bility. a dilemma illustrated by reactions to its proposals for assessing how an individual scientist on a government contract spends his time.

Initially HEW, conscious that Congress is pointing an accusing finger at auditing weaknesses, had proposed a regular system of 'personnel activity reports' based on after-the-fact reporting. University administrators. with the protests of scientists ringing in their ears, proposed an alternative system of pre-established 'monitored workloads' only major changes in which would have to be notified.

OMB has proposed a compromise. with monthly or even weekly activity reports for non-professional staff and student employees, while professional staff can select the monitored workload system. However neither HEW nor the universities are particularly happy about this, the former claiming insufficient checks and balances, the latter complaining of the burden on research scientists of having to certify the daily activities of laboratory technicians.

OMB's problems reflect a central issue facing the Carter Administration, namcly how to meet both Congress's demands for greater public accountability and promises to reduce the amount of government regulations and red tape. The dilemma is particularly acuse for a president who has claimed a special awareness of the problems facing the university research community, and has promised to make good the neglect of his immediate predecessors.

"What is so obviously lacking in these proposals in a national policy for basic research in higher education" claim two policy analysts, Frank Riddle and Janet D. Sweet at Stanford University. And it is partly in an effort to refute the charges that the administration is planning to take away with one hand what it is offering with the other, that Dr Press's Office of Science and Technology Policy has now become involved in the debate, attempting to provide a neutral channel of communication between the two sides.

The universities themselves are remaining far from inactive. The 107 member institutions of the National Association of College and University Business Officers (NACUBO) are, with the active support of the Association of American Universities, each preparing detailed estimates of the likely impact of the OMB proposals. The results of these surveys are being discussed this week at hastily-arranged meetings in Washington and Denver, and the conclusions will be presented to OMB at a meeting on 4 May.

Looking towards a longer perspective, the National Science Foundation is busy discussing with universities alternative patterns of research funding, for example investigating whether it would be possible to develop a legitimate way of "pooling" research funds from different sources to provide a particular research group with greater financial stability.

But given the intensity of the present debate. and OMB's insistence that it is not committed to the published proposals and is "quite prepared to change any part of them", its provisional goal of publishing a final version by mid-summer seems increasingly remote.

David Dickson 